\title{
Focus on ART
}

\section{Effects of embryo culture on global pattern of gene expression in preimplantation mouse embryos}

\author{
Paolo Rinaudo ${ }^{1,2}$ and Richard M Schultz ${ }^{1}$ \\ ${ }^{1}$ Department of Biology and ${ }^{2}$ Department of Obstetrics and Gynecology, University of Pennsylvania, Philadelphia, \\ PA 19104, USA
}

Correspondence should be addressed to R Schultz; Email: rschultz@sas.upenn.edu

\begin{abstract}
Culture of preimplantation embryos affects gene expression. The magnitude of the effect on the global pattern of gene expression, however, is not known. We compared global patterns of gene expression in blastocysts cultured from the one-cell stage in either Whitten's medium or KSOM + amino acids (KSOM/AA) with that of blastocysts that developed in vivo, using the Affymetrix MOE430A chip. The analysis revealed that expression of 114 genes was affected after culture in Whitten's medium, whereas only 29 genes were mis-expressed after culture in KSOM/AA. Expression Analysis Systematic Explorer was used to identify biological and molecular processes that are perturbed after culture and indicated that genes involved in protein synthesis, cell proliferation and transporter function were down-regulated after culture in Whitten's medium. A common set of genes involved in transporter function was also down-regulated after culture in KSOM/AA. These results provide insights as to why embryos develop better in KSOM/AA than in Whitten's medium, and highlight the power of microarray analysis to assess global patterns of gene expression.

Reproduction (2004) 128 301-311
\end{abstract}

\section{Introduction}

Preimplantation embryos can develop in media of composition ranging from simple balanced salt solutions and carbohydrates to very complex constituents (e.g. Ham's F-10) with the further addition of serum or a feeder layer of somatic cells (Lane 2001, Natale et al. 2001, Niemann \& Wrenzycki 2000). The blastocysts that develop after culture are known to be developmentally competent because, after embryo transfer, live offspring are born (Ecker et al. 2004). Nevertheless, embryo culture can perturb gene expression (Ho et al. 1995). Of particular note is that expression of imprinted genes appears particularly sensitive to culture conditions. For example, appropriate maternal monoallelic expression of $\mathrm{H} 19$ is observed after culture in $\mathrm{K}$ modified simplex optimized medium (KSOM) + amino acids (KSOM/AA), whereas biallelic expression is found after culture in Whitten's medium (WM) (Doherty et al. 2000). Moreover, biallelic expression is accompanied by loss of DNA methylation of cytosine residues on the paternal allele in the differentially methylated domain essential for repression of the paternal allele
(Doherty et al. 2000). We elected to assess the effect of embryo culture on global patterns of gene expression in embryos cultured in these two media using oligonucleotide microarrays, because of these aforementioned differences in maintaining or not maintaining appropriate monoallelic maternal H19 expression.

Until recently, quantitative analysis of high-resolution, two-dimensional protein gels (Latham et al. 1991), mRNA differential display (Ma et al. 2001), analysis of expressed sequence tags derived from libraries of various preimplantation stages (Ko et al. 2000, Sharov et al. 2003) and analysis of selected genes (Ho et al. 1995) have been used. Although these approaches have shed some light on the molecular basis underlying preimplantation development, they offer limited insight because only a small number of genes can be readily analyzed. Microarray techniques provide a powerful approach to study patterns of gene expression on a global scale (Hamatani et al. 2004, Wang et al. 2004). The ability to amplify the small amounts of mRNA present in preimplantation mouse embryos, which can only be isolated in limited numbers, makes it feasible to generate enough material for microarray analysis. We used Affymetrix oligonucleotide arrays (MOE430A chip) 
containing more than 22000 transcripts and variants, together with a T7-based linear double amplification method, and report here changes in the global patterns of gene expression that occurred during preimplantation development in mouse blastocysts cultured in WM or KSOM/AA from the one-cell stage. We report that, after culture in WM, 114 genes were mis-expressed, whereas only 29 were mis-expressed after culture in KSOM/AA. Of note is that 14 common genes were misexpressed in either medium and are involved in ion and water transport.

\section{Materials and Methods}

\section{Collection of preimplantation mouse embryos and RNA extraction}

Mouse CF-1 $\times$ B6D2F1/J embryos were isolated from superovulated mice as previously described (Zeng \& Schultz 2003). Briefly, CF-1 female mice were injected with $5 \mathrm{IU}$ equine chorionic gonadotrophin and $42-46 \mathrm{~h}$ later with $5 \mathrm{IU}$ human chorionic gonadotrophin (hCG); the females were then mated to B6D2F1/J males overnight. The next morning, zygotes were obtained from the ampullae and cultured in either WM (Whitten 1971) or KSOM/AA (Ho et al. 1995) to the blastocyst stage in 5\% $\mathrm{CO}_{2}-5 \% \mathrm{O}_{2}-90 \% \mathrm{~N}_{2}$ at $37^{\circ} \mathrm{C}$. Cultures were initiated with more embryos when WM was used, to compensate for the poorer development in WM compared with that in KSOM/AA. After culture in either medium, late-cavitating blastocysts of similar morphology were harvested at $96 \mathrm{~h}$ post-hCG. Embryos that developed in vivo were harvested $96 \mathrm{~h}$ post-hCG and those that looked morphologically similar to embryos that developed in vitro were collected and used for analysis. Cell numbers were determined by differential labeling of inner cell mass and trophectoderm cells as previously described (Handyside \& Hunter 1984). The numbers of total cells and of inner cell mass cells after culture in WM were $70.6 \pm 4.3$ (mean \pm S.E.M.) and $16.6 \pm 1.2$ respectively. Corresponding numbers after culture in KSOM/AA were $81.8 \pm 3.8$ and $23.9 \pm 1.7$ respectively. All animal experiments were approved by the Institutional Animal Care and Use Committee and were consistent with NIH guidelines.

Total RNA was extracted from pools of 80 embryos (120 ng total RNA) using Trizol containing $2 \mu$ l Pellet Paint (Novagen, Madison, WI, USA) according to the manufacturer's instructions (Invitrogen). Total RNA was dissolved in $10 \mu \mathrm{l}$ sterile water and stored at $-80^{\circ} \mathrm{C}$. RNA mass and size distribution were determined using the Agilent Bioanalyzer with RNA 6000 Nano LabChips (Palo Alto, CA, USA).

\section{cDNA preparation for microarray analysis}

Total RNA samples were submitted to the Penn Microarray Facility for target preparation and GeneChip hybridization. Total RNA yield was 74-133 ng per replicate pool. This total RNA was used for linear, two-round amplification by in vitro transcription (Affymetrix Small Sample Target Labeling Assay version II, www.affymetrix.com). cRNA yield after the first amplification was 1.5$5 \mu \mathrm{g}$, and $0.5 \mu \mathrm{g}$ of each replicate was used as input template for the second amplification. Final yield of biotinylated cRNA was $74-138 \mu \mathrm{g}$, of which $15 \mu \mathrm{g}$ per replicate was fragmented and hybridized to Affymetrix GeneChips. cRNA samples were hybridized to MOE430A GeneChip, then washed and stained on fluidics stations and scanned at $3 \mu \mathrm{m}$ resolution according to the manufacturer's instructions (GeneChip Analysis Technical Manual, www.affymetrix.com).

\section{Analysis of the microarrays}

Microarray Analysis Suite 5.0 (MAS; Affymetrix, Santa Clara, CA, USA) was used to quantify microarray signals with default analysis parameters and global scaling to target mean $=150$. Quality control parameters for all samples were within the following ranges: scale factor 1-2.7, background 42-88, percent genes detected $37-44 \%$ on $\mathrm{MOE} 430 \mathrm{~A}$, actin $3^{\prime} / 5^{\prime}$ signal ratio $1.5-2.8$, and GAPDH $3^{\prime} / 5^{\prime}$ signal ratio $2.3-7.5$. The MAS metrics output was loaded into GeneSpring v5 (Silicon Genetics, www.silicongenetics.com) with per-chip normalization to the 50th percentile and per-gene normalization to the median. A filtered list was created of all genes detected (MAS ' $\mathrm{P}$ ' call) in at least five of six replicates of the in vivo group.

Independent analyses were applied to identify genes with statistically significant differences in any of the two culture conditions (WM or KSOM/AA). The GeneSpring pairwise comparison (Welch t-test with ANOVA, $P=0.05$, Benjamini and Hochberg multiple testing correction) was conducted between all the possible pair combinations (in vivo, WM, KSOM/AA). The GeneSpring multi-class analysis was applied to the entire sample set (Welch $t$-test with Welch ANOVA, $P=0.05$, Benjamini and Hochberg multiple testing correction). A one-way ANOVA for microarrays (Igsun.grc.nia.nih. gov/ANOVA/index.html, default parameters) was also conducted. A non-redundant list was compiled containing candidate genes called significantly different in at least one analysis.

Genes exhibiting altered expression after culture were imported to Expression Analysis Systematic Explorer (EASE) to test for over-representation of annotation classes (Hosack et al. 2003). EASE is a program that provides statistical methods (reported as an EASE score) for discovering biological themes within gene lists, using previously published annotation databases. Over-representation does not refer to abundance of gene expression, but rather describes a class of genes that have similar functions - for example, transcription factors - regardless of their expression level, and appear more often in a list of interest 


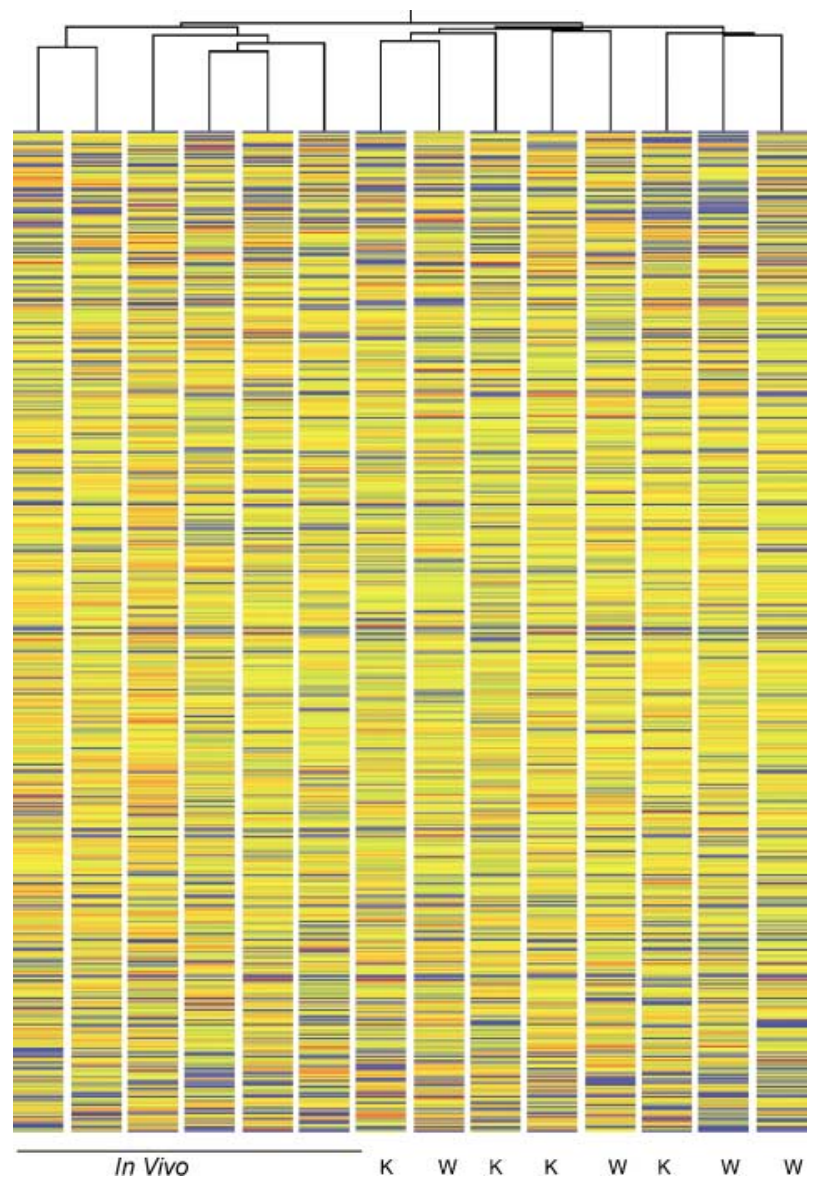

Figure 1 Hierarchical clustering analysis of all samples. Unsupervised clustering in GeneSpring was used to analyze similarities among replicate samples across all stages tested. Replicate sample numbers are indicated at the bottom of the figure. Colors correspond to relative RNA abundance for the $\sim 9000$ genes detected (Affymetrix 'Present' call), each of which is represented by one horizontal bar. W, Whitten's medium; K, KSOM + amino acids.

than would normally be predicted by their distribution among all genes assayed. The method incorporates jackknife iterative re-sampling of Fisher exact probabilities, with Bonferroni multiple testing corrections. An EASE score was calculated for likelihood of over-representation in the annotation categories GO Biological Process, GO Cell Component, GO Molecular Function, KEGG Pathway, and SwisProt keyword. GeneSpring 'genomes' were built for each of these annotation categories so that EASE scores
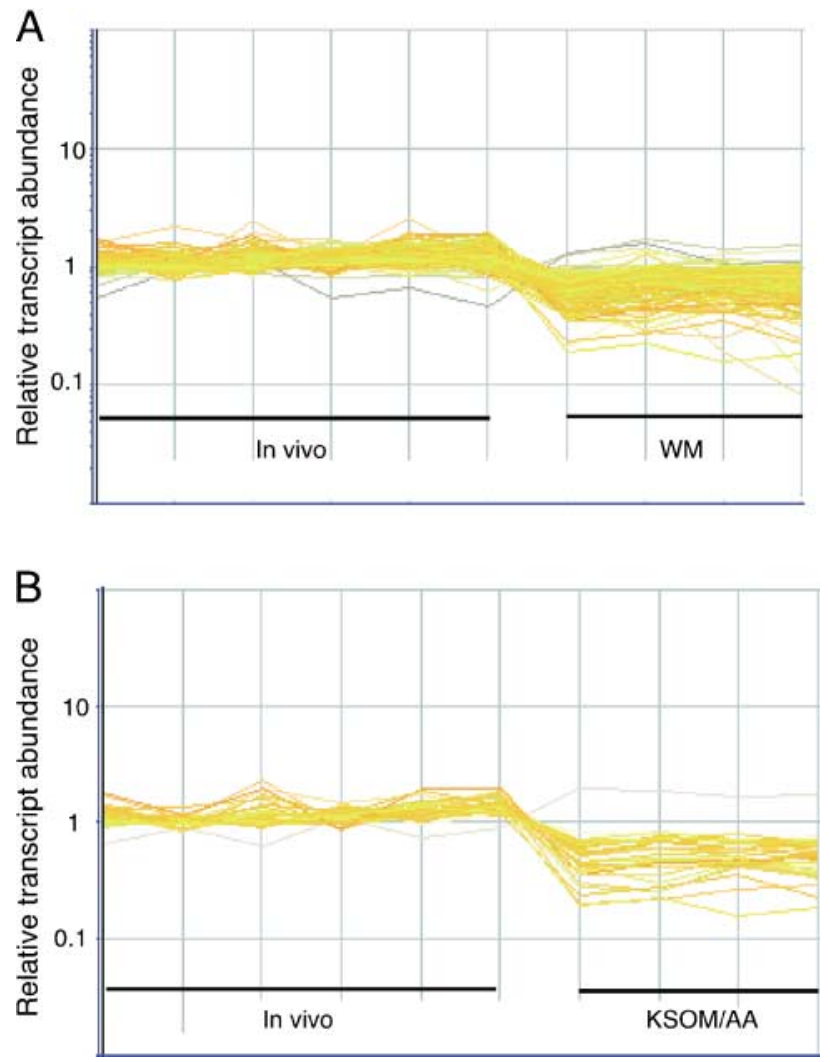

Figure 2 Differential expression profiles of genes after culture in either Whitten's medium (WM) (A) or KSOM/AA (KAA) (B).

from all subset lists could be visualized in parallel across all treatment and control groups, and pattern identification methods similar to those applied at the gene level were used to find functional themes in the data set. All reported expression differences from gene-based or annotationbased profiling were re-tested for statistical significance by multi-class ANOVA as appropriate.

\section{Real time RT-PCR analysis}

Blastocysts developed in vivo and in vitro (WM and KSOM/AA) were collected as described above and total RNA was isolated. Two embryo equivalents of template RNA were used for each real-time RT-PCR assay according to the manufacturer's procedure using ABI Prism Sequence Detection System 7000 (Applied Biosystems, Foster City,

Table 1 Genes up-regulated after culture in Whitten's medium.

\begin{tabular}{llll}
\hline Fold change & Gene symbol & Gene name & Unigene number \\
\hline 2.648 & Spnb2 & beta-spectrin 2, non-erythrocytic & Mm.123110 \\
2.193 & Nsap1l-(pending) & NS1-associated protein 1-like & $M m .196461$ \\
1.616 & 2610016C23Rik & RIKEN cDNA 2610016C23 gene & $M .34156$ \\
1.595 & Ptprs & protein tyrosine phosphatase, receptor type, S & $M m .258771$ \\
1.461 & Ptpns1 & protein tyrosine phosphatase, non-receptor type substrate 1 & $\mathrm{Mm} .4420$ \\
1.276 & Ptpn21 & protein tyrosine phosphatase, non-receptor type 21 & $\mathrm{Mm} .1682$ \\
\hline
\end{tabular}


Table 2 Genes down-regulated after culture in Whitten's medium.

\begin{tabular}{|c|c|c|c|}
\hline Fold change & Gene symbol & Gene name & Unigene number \\
\hline 0.14 & 5730469M10Rik & RIKEN cDNA 5730469M10 gene & Mm.27227 \\
\hline 0.20 & Snap91 & synaptosomal-associated protein, $91 \mathrm{kDa}$ & Mm.4870 \\
\hline 0.21 & Ndr1 & $\mathrm{N}$-myc downstream regulated 1 & Mm.4063 \\
\hline 0.21 & 9030418M05Rik & RIKEN cDNA 9030418M05 gene & Mm.45994 \\
\hline 0.26 & Ptk6 & PTK6 protein tyrosine kinase 6 & Mm.4497 \\
\hline 0.27 & $\mathrm{Ndrl}$ & $\mathrm{N}$-myc downstream regulated 1 & Mm.30837 \\
\hline 0.27 & Ccnd1 & cyclin D1 & Mm.22288 \\
\hline 0.28 & Msx1 & homeo box, msh-like 1 & Mm.259122 \\
\hline 0.30 & Slc7a3 & $\begin{array}{l}\text { solute carrier family } 7 \text { (cationic amino acid } \\
\text { transporter, y }+ \text { system), member } 3\end{array}$ & Mm.5140 \\
\hline 0.31 & S100a10 & S100 calcium binding protein A10 (calpactin) & Mm.1 \\
\hline 0.31 & Aqp8 & aquaporin 8 & Mm.9970 \\
\hline 0.33 & & $\begin{array}{l}\text { EST, weakly similar to CAMP [Mus musculus] } \\
\text { [M.musculus] }\end{array}$ & Mm.270928 \\
\hline 0.34 & Lcp1 & lymphocyte cytosolic protein 1 & Mm.153911 \\
\hline 0.34 & 116 & interleukin 6 & Mm.1019 \\
\hline 0.35 & Pip5k2a & phosphatidylinositol-4-phosphate 5-kinase, type II, alpha & Mm.8771 \\
\hline 0.36 & 1810018M05Rik & RIKEN cDNA 1810018M05 gene & Mm.29379 \\
\hline 0.38 & Tdgf1 & teratocarcinoma-derived growth factor & Mm.5090 \\
\hline 0.40 & & hypothetical protein C030011B15 & Mm.202715 \\
\hline 0.40 & Arhu & ras homolog gene family, member $U$ & Mm.28954 \\
\hline 0.40 & Efnb1 & ephrin B1 & Mm.3374 \\
\hline 0.41 & Upp & uridine phosphorylase & Mm.4610 \\
\hline 0.42 & Car4 & carbonic anhydrase 4 & Mm.1641 \\
\hline 0.43 & S/c15a2 & solute carrier family $15(\mathrm{H}+$ /peptide transporter), member 2 & Mm.63479 \\
\hline 0.44 & C77258 & eomesodermin homolog (Xenopus laevis) & Mm.200692 \\
\hline 0.45 & 1810017F1ORik & RIKEN cDNA $1810017 F 10$ gene & Mm.25295 \\
\hline 0.46 & Lgals3 & lectin, galactose binding, soluble 3 & Mm.2970 \\
\hline 0.46 & Nid1 & nidogen 1 & Mm.4691 \\
\hline 0.47 & Coni & cyclin I & Mm.22711 \\
\hline 0.47 & Cldn6 & claudin 6 & Mm.86421 \\
\hline 0.47 & Tex20 & testis expressed gene 20 & Mm.28388 \\
\hline 0.47 & Btg1 & B-cell translocation gene 1 , anti-proliferative & Mm.16596 \\
\hline 0.47 & D6Ertd263e & DNA segment, Chr 6, ERATO Doi 263, expressed & Mm.195955 \\
\hline 0.48 & Fem1b & feminization 1 homolog $b$ (C. elegans) & Mm.24069 \\
\hline 0.48 & Np95 & nuclear protein 95 & Mm.42196 \\
\hline 0.48 & Niban & niban protein & Mm.157700 \\
\hline 0.48 & Ube2a & $\begin{array}{l}\text { ubiquitin-conjugating enzyme E2A, } \\
\text { RAD6 homolog ( } S \text {. cerevisiae) }\end{array}$ & Mm.27541 \\
\hline 0.49 & Grh/1-(pending) & grainyhead like 1 (Drosophila) & Mm.25552 \\
\hline 0.49 & Gpx1 & glutathione peroxidase 1 & Mm.1090 \\
\hline 0.49 & $D k k 1$ & dickkopf homolog 1 (Xenopus laevis) & Mm.7960 \\
\hline 0.49 & Tgut-(pending) & tRNA-guanine transglycosylase & Mm.24178 \\
\hline 0.50 & Enpp1 & ectonucleotide pyrophosphatase/phosphodiesterase 1 & Mm.27254 \\
\hline 0.50 & Atp6v0c & ATPase, $\mathrm{H}+$ transporting, $\mathrm{V} 0$ subunit $\mathrm{C}$ & Mm.30155 \\
\hline 0.50 & 1110013H04Rik & RIKEN cDNA $1110013 \mathrm{H} 04$ gene & Mm.7863 \\
\hline 0.51 & Rp/13a & ribosomal protein L13a & Mm.180458 \\
\hline 0.51 & Ftl1 & ferritin light chain 1 & Mm.7500 \\
\hline 0.52 & Spp1 & secreted phosphoprotein 1 & Mm.260317 \\
\hline 0.52 & D10Ucla1 & $\begin{array}{l}\text { DNA segment, Chr 10, University of } \\
\text { California at Los Angeles } 1\end{array}$ & Mm.41272 \\
\hline 0.52 & Lamr1 & Laminin receptor 1 & Mm.4071 \\
\hline 0.53 & Oaz1 & ornithine decarboxylase antizyme & Mm.683 \\
\hline 0.53 & Tex19 & testis expressed gene 19 & Mm.12669 \\
\hline 0.53 & Ftl2 & ferritin light chain 2 & Mm.30357 \\
\hline 0.54 & Ldh1 & lactate dehydrogenase 1 , A chain & Mm.29324 \\
\hline 0.54 & D16Bwg1494e & hypothetical protein MNCb-4137 & Mm.246388 \\
\hline 0.54 & Ephx2 & epoxide hydrolase 2, cytoplasmic & Mm.15295 \\
\hline 0.54 & $T_{C} / 1$ & T-cell lymphoma breakpoint 1 & Mm.18154 \\
\hline 0.54 & Slc15a2 & $\begin{array}{l}\text { solute carrier family } 15 \\
\text { (H+/peptide transporter), member } 2\end{array}$ & Mm.63479 \\
\hline 0.55 & $\operatorname{Rps} 8$ & ribosomal protein S8 & Mm.3381 \\
\hline 0.56 & Plp2 & proteolipid protein 2 & Mm.18565 \\
\hline 0.56 & Pla2g10 & phospholipase $A 2$, group $X$ & Mm.4214 \\
\hline 0.56 & Рpap2a & phosphatidic acid phosphatase $2 \mathrm{a}$ & Mm.2598 \\
\hline 0.56 & MGC36305 & hypothetical protein MGC36305 & Mm.203937 \\
\hline 0.56 & Ppp1ca & $\begin{array}{l}\text { protein phosphatase } 1 \text {, catalytic } \\
\text { subunit, alpha isoform }\end{array}$ & Mm.1970 \\
\hline
\end{tabular}


Table 2 Continued

\begin{tabular}{|c|c|c|c|}
\hline Fold change & Gene symbol & Gene name & Unigene number \\
\hline 0.57 & MGC27616 & hypothetical protein MGC27616 & Mm.50610 \\
\hline 0.57 & Osgep & O-sialoglycoprotein endopeptidase & Mm.29642 \\
\hline 0.57 & S100a10 & S100 calcium binding protein A10 (calpactin) & Mm.1 \\
\hline 0.57 & Gpx4 & glutathione peroxidase 4 & Mm.2400 \\
\hline 0.57 & 1500032D16Rik & RIKEN cDNA 1500032D16 gene & Mm.28349 \\
\hline 0.57 & Hmg2Ob & high mobility group $20 \mathrm{~B}$ & Mm.38474 \\
\hline 0.57 & Slc16a1 & $\begin{array}{l}\text { solute carrier family } 16 \\
\text { (monocarboxylic acid transporters), member } 1\end{array}$ & Mm.9086 \\
\hline 0.58 & Prss 8 & protease, serine, 8 (prostasin) & Mm.5875 \\
\hline 0.58 & 4930471M23Rik & RIKEN cDNA 4930471M23 gene & Mm.247985 \\
\hline 0.58 & Rps17 & ribosomal protein S17 & Mm.42767 \\
\hline 0.58 & 2410015N17Rik & RIKEN cDNA 2410015N17 gene & Mm.29898 \\
\hline 0.58 & MGC28180 & Mus musculus, clone IMAGE:3995663, mRNA & Mm.267131 \\
\hline 0.59 & Rp/13a & ribosomal protein L13a & Mm.180458 \\
\hline 0.59 & Prkcz & protein kinase $C$, zeta & Mm.28561 \\
\hline 0.60 & Nap1/1 & nucleosome assembly protein 1 -like 1 & Mm.3797 \\
\hline 0.61 & Rpl10a & ribosomal protein L10A & Mm.2424 \\
\hline 0.61 & 1110020C13Rik & RIKEN cDNA $1110020 C 13$ gene & Mm.29865 \\
\hline 0.62 & $\operatorname{lgf} 2 b p 1$ & insulin-like growth factor 2 , binding protein 1 & Mm.12919 \\
\hline 0.63 & Renbp & renin binding protein & Mm.28280 \\
\hline 0.63 & Lsm4-(pending) & U6 snRNA-associated SM-like protein 4 & Mm.14585 \\
\hline 0.63 & $\operatorname{Prd} \times 2$ & peroxiredoxin 2 & Mm.42948 \\
\hline 0.63 & 5730578NO8Rik & RIKEN cDNA 5730578N08 gene & Mm.46480 \\
\hline 0.64 & Tmsb10 & thymosin, beta 10 & Mm.3532 \\
\hline 0.65 & Dlg5 & discs, large homolog 5 (Drosophila) & Mm.68971 \\
\hline 0.65 & Taldo1 & transaldolase 1 & Mm.29182 \\
\hline 0.65 & Scotin-(pending) & scotin gene & Mm.196533 \\
\hline 0.66 & Klf9 & Kruppel-like factor 9 & Mm.19788 \\
\hline 0.66 & Ssfa1 & sperm specific antigen 1 & Mm.29504 \\
\hline 0.67 & Ifi30 & interferon gamma inducible protein 30 & Mm.30241 \\
\hline 0.67 & $2410002 K 23 R i k$ & RIKEN cDNA 2410002K23 gene & Mm.182051 \\
\hline 0.67 & Gnb2-rs1 & $\begin{array}{l}\text { guanine nucleotide binding protein, } \\
\text { beta } 2 \text {, related sequence } 1\end{array}$ & Mm.5305 \\
\hline 0.67 & Rps17 & ribosomal protein S17 & Mm.42767 \\
\hline 0.67 & 2310009N05Rik & RIKEN cDNA 2310009N05 gene & Mm.29247 \\
\hline 0.68 & Ran & RAN, member RAS oncogene family & Mm.7521 \\
\hline 0.68 & O610011C19Rik & RIKEN cDNA 0610011C19 gene & Mm.27792 \\
\hline 0.68 & Rps14 & ribosomal protein $\mathrm{S} 14$ & Mm.43778 \\
\hline 0.68 & Rp/13 & ribosomal protein L13 & Mm.42578 \\
\hline 0.68 & D11Ertd672e & $\begin{array}{l}\text { DNA segment, Chr 11, ERATO } \\
\text { Doi } 672 \text {, expressed }\end{array}$ & Mm.27670 \\
\hline 0.68 & $A c t b$ & actin, beta, cytoplasmic & Mm.297 \\
\hline 0.69 & Txn1 & thioredoxin 1 & Mm.1275 \\
\hline 0.69 & 1300011C24Rik & RIKEN cDNA 1300011C24 gene & Mm.186 \\
\hline 0.69 & Dnajb1 & Dnal (Hsp40) homolog, subfamily B, member 1 & Mm.2982 \\
\hline 0.70 & LOC224023 & similar to RIKEN cDNA $1200009 K 10$ & Mm.38788 \\
\hline 0.72 & Ptdsr & Phosphatidylserine receptor & Mm.24997 \\
\hline 0.73 & $D X \operatorname{Im} \times 38 e$ & DNA segment, Chr X, Immunex 38, expressed & Mm.28850 \\
\hline 0.73 & Rps5 & ribosomal protein $\mathrm{S} 5$ & Mm.5291 \\
\hline
\end{tabular}

CA, USA). To confirm the ability of this microarray analysis to resolve the differences in expression level, three genes that showed a statistically significant decrease were selected. The corresponding ABI TaqMan Assay-onDemand probe/primer sets used were Mm00431846-m1 (Aqp8), Mm00500526-m1 (Slc7a3) and Mm00451610 (SlC15a2). Three replicates were used for each real-time PCR reaction; a minus template served as control. Quantification was normalized to a constant amount of pEGFPN2 RNA spiked into the RNA cocktail before the RNA extraction. Data were analyzed within the log-linear phase of the amplification curve obtained for each probe/ primer using the comparative CT method (ABI PRISM 7700 Sequence Detection System, User Bulletin no. 2).

\section{Results and Discussion \\ Hierarchical cluster analysis}

Blastocysts that developed after culture from the one-cell stage in either WM or KSOM/AA (four replicates of each) or blastocysts that developed in vivo (six replicates) were used for expression profiling. We elected to initiate culture at the one-cell stage, rather than the twocell stage, as in the previous study that assessed the 


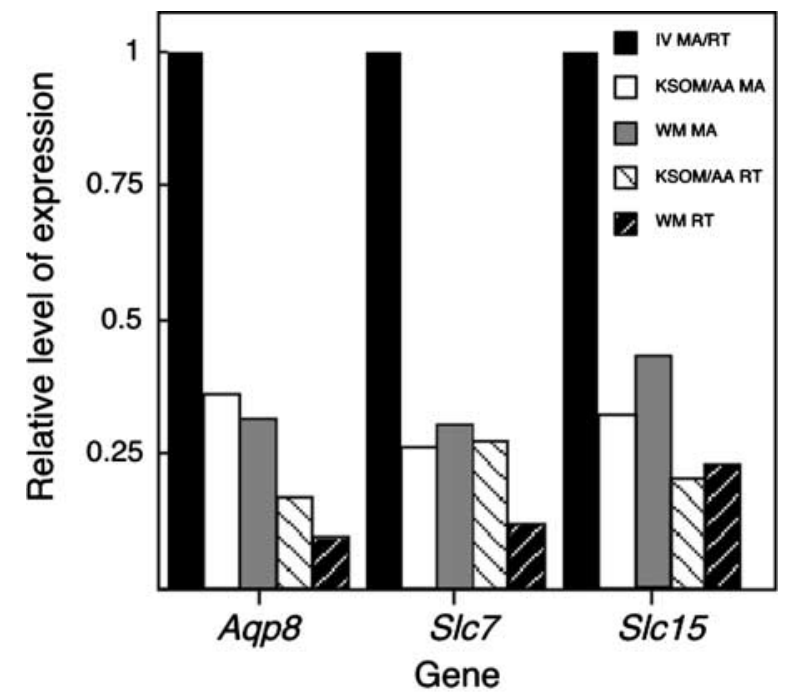

Figure 3 Real-time PCR verification of microarray data. Three genes exhibiting decreased expression after culture in either WM or KSOM/ AA were selected for analysis. The level of expression relative to embryos that developed in vivo by either microarray analysis or realtime PCR was set as 1. IV MA/RT, relative level of expression by embryos that developed in vivo (IV), assessed by either microarray (MA) or real-time (RT) PCR; KSOM/AA MA and KSOM/AA RT, relative levels of expression after culture in KSOM/AA assessed by MA or RT respectively; WM MA and WM RT, relative levels of expression after culture in WM assessed by MA or RT respectively.

effect of culture on expression of H19 (Doherty et al. 2000), because the experimental design of many studies incorporates culture initiating at the one-cell stage. Moreover, culture initiated at the one-cell stage more closely mimics the experimental procedures performed in human IVF clinics.

An unsupervised hierarchical clustering was performed using genes that were present at least in five of six in vivo control groups. Of the 22690 genes present on the MOE430A chip, we found that, on average, $39.2 \%$ were present in at least five of six in vivo replicates, and three of four WM or KSOM/AA replicates respectively. Although, the clustering dendrogram revealed that the embryos that developed in vivo clustered together, embryos cultured in either WM or KSOM/AA did not (Fig. 1). Analysis of the branch tree distances revealed that only minimal differences existed between the WM and KSOM/AA group and overall between the in vivo group and the cultured groups: the minimal branch distance between the in vivo replicates was 0.354 and the final clustering branch was close to one (0.999). Instead, the cultured groups had a minimal branch distance of 0.544 and the more distant replicates branched at a distance of 1.027. This suggests that, although embryo culture leads to perturbations in global patterns of gene expression, the differences between the expression profiles for embryos cultured under the two different conditions are actually quite small.

\section{Effect of culture in WM on gene expression}

Expression of 114 genes $(114 / 8868=1.28 \%)$ was statistically different between the two groups and satisfied the post hoc correction (Fig. 2) when GeneSpring pairwise comparison (Welch $t$-test with ANOVA, $P=0.05$, Benjamini and Hochberg multiple testing correction) was conducted between the control group and the WM group. It is possible that some of the differences observed after culture in WM (or KSOM/AA) are sex-specific. Of these genes, only six were up-regulated (Table 1), whereas 108 were down-regulated (Table 2 ). It is interesting to note that only $2 / 6(33 \%)$ and $41 / 108(38 \%)$ were up-regulated or down-regulated more than twofold - that is, many of the changes were small. It is becoming more widely appreciated that modest changes in the expression of a gene can result in profound differences. An example is that changing the expression of the transcription factor OCT4 by $50 \%$ can result in changes in cell differentiation (Niwa et al. 2000). Thus small changes in expression of a critical transcription factor or a gene that acts in the early steps of a signal transduction pathway could function as a molecular switch that would lead to widespread and dramatic changes in gene expression.

To confirm that the differences detected from the microarray analyses were real, three genes that exhibit decreased expression after culture in either WM or KSOM/AA (see below) were selected for real-time PCR analysis. Results of this experiment confirmed that a decrease in expression was observed (Fig. 3), strongly suggesting that the changes in gene expression observed from the microarray analyses are valid.

EASE analysis using GO Biological Process and other annotation categories was implemented to ascertain if any biological theme(s) could be discovered from the list of genes with expression altered by culture in WM. EASE analysis identified five such biological processes: ribosome biogenesis and protein synthesis, cell organization and biogenesis, apoptosis, regulation of cell cycle and proliferation, and selenium binding (Table 3). Note that genes can be common to more than one process (e.g. Rp13).

Formation of a functional ribosome requires exquisite coordinate expression of rRNA and ribosomal proteins. Decreased expression of several ribosomal proteins for both the large and small subunits would adversely affect ribosome biogenesis, which would in turn have a negative effect on the rate of protein synthesis and development. For example, cyclin synthesis is required for cell proliferation and decreasing the rate of protein synthesis would inevitably slow down the rate of cell proliferation. In fact, culture in KSOM/AA results in blastocysts that have greater cell numbers when compared with blastocysts that develop in media that do not contain amino acids (Erbach et al. 1994, Ho et al. 1995, Biggers et al. 2000, Summers et al. 2000). The reduced level of expression of cyclin D1, which regulates cell cycle progression (Stacey 2003), and of Ran, which is involved in spindle formation (Kalab et al. 
Table 3 EASE analysis of differentially expressed genes after culture in Whitten's medium.

\begin{tabular}{|c|c|c|}
\hline EASE gene category & Gene symbol & Gene name \\
\hline \multirow[t]{13}{*}{ Ribosome biogenesis and protein synthesis } & Rps8 & ribosomal protein S8 \\
\hline & Rp/13 & ribosomal protein L13 \\
\hline & Rpl13a & ribosomal protein $\mathrm{L} 13 \mathrm{a}$ \\
\hline & Rps17 & ribosomal protein $\mathrm{S} 17$ \\
\hline & Rps14 & ribosomal protein $\mathrm{S} 14$ \\
\hline & Rps5 & ribosomal protein S5 \\
\hline & Rpl10a & ribosomal protein $\mathrm{L} 10 \mathrm{a}$ \\
\hline & Ssfa1 & sperm specific antigen 1 \\
\hline & Lsm4 & LSM4 homolog, U6 small nuclear RNA associated \\
\hline & $2610016 C 23 R i k$ & RIKEN CDNA 2610016C23 gene \\
\hline & Syncrip & synaptotagmin binding, cytoplasmic RNA interacting protein \\
\hline & Qtrt1 & queuine tRNA-ribosyltransferase 1 \\
\hline & $P 5 \mathrm{cr} 2$ & pyrroline-5-carboxylate reductase \\
\hline \multirow[t]{14}{*}{ Cell organization and biogenesis } & $G p \times 4$ & glutathione peroxidase 4 \\
\hline & Actb & actin, beta, cytoplasmic \\
\hline & Atp6v0C & ATPase, $\mathrm{H}+$ transporting, $\mathrm{V} 0$ subunit $\mathrm{C}$ \\
\hline & Ptpns1 & Protein tyrosine phosphatase, non receptor type substrate 1 \\
\hline & Rps8 & ribosomal protein S8 \\
\hline & Tmsb10 & thymosin, beta 10 \\
\hline & Nap1/1 & nucleosome assembly protein 1 -like 1 \\
\hline & Rp/13 & ribosomal protein L13 \\
\hline & Rps17 & ribosomal protein $\mathrm{S} 17$ \\
\hline & Rps14 & ribosomal protein S14 \\
\hline & Rps5 & ribosomal protein S5 \\
\hline & Ran & RAN, member RAS oncogene family \\
\hline & Arhu & Ras homolog gene family, member $U$ \\
\hline & Ррар2а & phosphatidic acid phosphatase $2 \mathrm{a}$ \\
\hline \multirow[t]{8}{*}{ Apoptosis } & $G p \times 1$ & glutathione peroxidase 1 \\
\hline & Fem $1 b$ & feminization 1 homolog b (C. elegans) \\
\hline & Prkcz & protein kinase $\mathrm{C}$, zeta \\
\hline & $\operatorname{Prd} 22$ & peroxiredoxin 2 \\
\hline & Spp1 & secreted phosphoprotein 1 \\
\hline & 6430628105 Rik & RIKEN cDNA 6430628105 gene \\
\hline & Ptdsr & phosphatidylserine receptor \\
\hline & Hip1 & huntingtin interacting protein 1 \\
\hline \multirow[t]{12}{*}{ Regulation of cell proliferation } & Spp1 & secreted phosphoprotein 1 \\
\hline & Tdgf1 & teratocarcinoma-derived growth factor \\
\hline & Nap1/1 & nucleosome assembly protein 1 -like 1 \\
\hline & 0610011C19Rik & RIKEN cDNA 0610011 C19 gene \\
\hline & Btg1 & B-cell translocation gene 1, anti-proliferative \\
\hline & Ccnd1 & cyclin D1 \\
\hline & Coni & cyclin I \\
\hline & Np95 & nuclear protein 95 \\
\hline & Ppp1ca & protein phosphatase 1 , catalytic subunit, alpha isoform \\
\hline & Ran & RAN, member RAS oncogene family \\
\hline & 9030418M05Rik & RIKEN cDNA 9030418M05 gene \\
\hline & Arhu & Ras homolog gene family, member $U$ \\
\hline \multirow[t]{3}{*}{ Selenium binding } & $G p \times 1$ & glutathione peroxidase 1 \\
\hline & Gpx4 & glutathione peroxidase 4 \\
\hline & $\operatorname{Prd} 22$ & peroxiredoxin 2 \\
\hline
\end{tabular}

1999) and essential for the nuclear import and export cycle (Quimby \& Dasso 2003), could also contribute to retarded development in vitro. In a similar vein, reduced expression of claudin (Table 2) and protein kinase C (PKC) $\zeta$, which is an atypical PKC (Tables 2 and 3), may perturb tight junction assembly and function. Tight junction formation, which initiates after compaction, establishes a permeability seal in the trophectoderm that is essential for vectorial fluid transport and blastocoel formation (Fleming et al. 2001, Watson \& Barcroft 2001). Claudin is a component of tight junctions (Tepass 2003) and PKC $\zeta$, in association with PAR3 and PAR6, localizes with the tight junction protein, ZO-1 (Suzuki et al. 2001); the role of this complex in tight junction assembly or function is unknown.

Decreased expression of secreted phosphoprotein 1 (osteopontin) (Tables 2 and 3), could, in principle, contribute to reduced implantation. Osteoponin contains a GRGDS amino acid sequence that can mediate adhesion to specific integrins implicated in implantation (Lessey 2002). It is unlikely that modest reductions in expression of these genes results in compromised implantation, because a recent study noted no decrease in the incidence of implantation and development to term after embryo transfer of WM-cultured embryos (Ecker et al. 2004). 
Table 4 Genes down-regulated after culture in KSOM/AA.

\begin{tabular}{|c|c|c|c|}
\hline Fold change & Common symbol & Gene name & Unigene \\
\hline 0.16 & 5730469M10Rik & RIKEN cDNA 5730469M10 gene & Mm.27227 \\
\hline 0.17 & $2210417006 R i k$ & RIKEN cDNA 2210417006 gene & Mm.25353 \\
\hline 0.21 & 9030418M05Rik & RIKEN cDNA 9030418M05 gene & Mm.45994 \\
\hline 0.26 & Morc & microrchidia & Mm.26875 \\
\hline 0.26 & Slc7a3 & solute carrier family 7 (cationic amino acid transporter, $y+$ system), member 3 & Mm.5140 \\
\hline 0.29 & Ndrl & N-myc downstream regulated 1 & Mm.30837 \\
\hline 0.29 & Rp/13a & ribosomal protein L13a & Mm.180458 \\
\hline 0.32 & 116 & interleukin 6 & Mm.1019 \\
\hline 0.32 & Slc15a2 & solute carrier family $15(\mathrm{H}+$ /peptide transporter), member 2 & Mm.63479 \\
\hline 0.33 & Ndr1 & $\mathrm{N}$-myc downstream regulated 1 & Mm.4063 \\
\hline 0.36 & Aqp8 & aquaporin 8 & Mm.9970 \\
\hline 0.40 & Arhu & ras homolog gene family, member $U$ & Mm.28954 \\
\hline 0.40 & Asns & asparagine synthetase & Mm.2942 \\
\hline 0.41 & Fem $1 b$ & feminization 1 homolog b (C. elegans) & Mm.24069 \\
\hline 0.49 & Blnk & B-cell linker & Mm.9749 \\
\hline 0.49 & Tex20 & testis expressed gene 20 & Mm.28388 \\
\hline 0.50 & MGC38363 & transmembrane 4 superfamily member 3 & Mm.22270 \\
\hline 0.52 & Ugp2 & UDP-glucose pyrophosphorylase 2 & Mm.28877 \\
\hline 0.52 & B4galt6 & UDP-Gal:betaGlcNAc beta 1,4-galactosyltransferase, polypeptide 6 & Mm.26364 \\
\hline 0.55 & Tpm1 & tropomyosin 1 , alpha & Mm.121878 \\
\hline 0.57 & Nupr1 & nuclear protein 1 & Mm.18742 \\
\hline 0.59 & Oaz1 & ornithine decarboxylase antizyme & Mm.683 \\
\hline 0.59 & Map17-(pending) & membrane-associated protein 17 & Mm.30181 \\
\hline 0.60 & $\operatorname{Prd} 22$ & peroxiredoxin 2 & Mm.42948 \\
\hline 0.61 & Lamr1 & Laminin receptor 1 & Mm.4071 \\
\hline 0.61 & $R w 1$-(pending) & RW1 protein & Mm.10808 \\
\hline 0.64 & Rab11b & RAB11B, member RAS oncogene family & Mm.35727 \\
\hline 0.65 & Slc2a3 & solute carrier family 2 (facilitated glucose transporter), member 3 & Mm.3726 \\
\hline
\end{tabular}

Expression of teratocarcinoma-derived growth factor (Tdgf1) (Tables 2 and 3) and Msx1 (Hox7) (Table 2) was also reduced after culture in WM. Tdgf1 may be an important regulatory gene in gastrulation and early specification of tissues and organs (Xu et al. 1999). Tdgf1 deficiency leads to abnormal failure of cardiomyocytes to differentiate and embryo lethality. Msx1 is a homeobox gene the expression of which is regulated by BMP signaling and is expressed in several developing organs in vertebrates, including the facial primordia, particularly at the sites where epithelial-mesenchymal interactions occur during organogenesis (Liu et al. 2004). The function of either Tdgf1 or Msx1 in preimplantation is not known.

\section{Effect of culture in KSOM/AA on gene expression}

After culture in KSOM/AA, expression of only 29 genes was affected when compared with embryos that developed in vivo (Fig. 2). One gene (CD81) was up-regulated, whereas the others were down-regulated (Table 4); the significance of CD81 up-regulation, which is involved in signal transduction and cell adhesion in the immune system (Levy et al. 1998) and possibly sperm-egg fusion (Takahashi et al. 2001), is not apparent. The lower number of genes mis-expressed in KSOM/AA than in WM is consistent with KSOM/AA supporting better development in vitro. EASE analysis revealed that S/C7a3, Slc15a2, Aqp8, Slc2a3, Cd81, Arhu and Asns were over-represented (Table 5). The common feature of these genes is that they

Table 5 EASE analysis of genes differentially expressed after culture in KSOM/AA.

\begin{tabular}{|c|c|c|}
\hline EASE gene category & Gene symbol & Gene name \\
\hline \multirow[t]{4}{*}{ Carrier activity } & Slc7a3 & solute carrier family 7 (cationic amino acid transporter, $y+$ system), member 3 \\
\hline & Slc15a2 & solute carrier family $15(\mathrm{H}+$ /peptide transporter), member 2 \\
\hline & 9030418M05Rik & RIKEN cDNA 9030418M05 gene \\
\hline & Slc2a3 & solute carrier family 2 (facilitated glucose transporter), member 3 \\
\hline \multirow[t]{7}{*}{ Localized to plasma membrane } & $C d 81$ & Cd81 antigen \\
\hline & Slc7a3 & solute carrier family 7 (cationic amino acid transporter, $y+$ system), member 3 \\
\hline & Slc15a2 & solute carrier family $15(\mathrm{H}+$ /peptide transporter), member 2 \\
\hline & Aqp8 & aquaporin 8 \\
\hline & Slc2a3 & solute carrier family 2 (facilitated glucose transporter), member 3 \\
\hline & Arhu & ras homolog gene family, member $U$ \\
\hline & Asns & asparagine synthetase \\
\hline
\end{tabular}


Table 6 Genes differentially expressed after culture in either Whitten's medium or KSOM/AA.

\begin{tabular}{|c|c|c|}
\hline Common name & Description & Unigene \\
\hline Rp/13a & ribosomal protein $\mathrm{L} 13 \mathrm{a}$ & Mm.180458 \\
\hline $\operatorname{Prd} \times 2$ & peroxiredoxin 2 & Mm.42948 \\
\hline Lamr1 & Laminin receptor 1 & Mm.4071 \\
\hline Oaz1 & ornithine decarboxylase antizyme & Mm.683 \\
\hline Tex20 & testis expressed gene 20 & Mm.28388 \\
\hline Arhu & $\begin{array}{l}\text { ras homolog gene family, } \\
\text { member } U\end{array}$ & Mm.28954 \\
\hline Fem $1 b$ & $\begin{array}{l}\text { feminization } 1 \text { homolog b } \\
\text { (C. elegans) }\end{array}$ & Mm.24069 \\
\hline Aqp8 & Aquaporin 8 & Mm.9970 \\
\hline Ndr1 & $\mathrm{N}$-myc downstream regulated 1 & Mm.4063 \\
\hline Slc15a2 & $\begin{array}{l}\text { solute carrier family } 15 \\
\text { (H+/peptide transporter), } \\
\text { member } 2\end{array}$ & Mm.63479 \\
\hline 116 & interleukin 6 & Mm.1019 \\
\hline Slc7a3 & $\begin{array}{l}\text { solute carrier family } 7 \\
\quad \text { (cationic amino acid transporter, } \\
\text { y+ system), member } 3\end{array}$ & Mm.5140 \\
\hline $\mathrm{Ndrl}$ & $\mathrm{N}$-myc downstream regulated 1 & Mm.30837 \\
\hline 9030418M05Rik & RIKEN cDNA 9030418M05 gene & Mm.45994 \\
\hline
\end{tabular}

are involved in membrane transport function. Interestingly, expression of $S / C 2 a 3$ was altered by culture in KSOM/AA but not in WM. Slc2a3 is also known as Glut3, which is involved in facilitating glucose transport.

Inclusion of amino acids in KSOM has several positive effects on preimplantation development in vitro. For example, blastocyst cell number is increased, cavitation occurs earlier, and a greater fraction of blastocysts hatch (Ho et al. 1995, Biggers et al. 2000). Consistent with these beneficial effects is that there are only minor changes in the global pattern of gene expression after culture in KSOM/AA, although it is formally possible that the differences in salt and energy source concentrations may underlie the changes in gene expression. Recent studies have suggested, however, that ammonia generated by hydrolysis of glutamine in the culture medium may promote deleterious effects on embryo development, and experimentally increasing the ammonia concentrations compromises embryo development (Lane \& Gardner 2003). Asparagine synthase (Asns), which catalyzes the ATP-dependent formation of asparagine from aspartate and ammonia, is down-regulated and could impair the ability of the embryo to convert ammonia to a non-toxic form. Nevertheless, results presented here suggest that inclusion of amino acids in KSOM is unlikely to compromise developmental competence - that is, the ability of transferred blastocysts to implant and develop to term because the global pattern of gene expression is very similar to that of embryos that develop in vivo. Current experiments examining the effect on global patterns of gene expression of including amino acids in WM and omitting them from KSOM should provide information about the role of amino acids in governing gene expression in cultured embryos.

\section{Common genes mis-expressed after culture in either WM or KSOM/AA}

Analysis of the data in Tables 2 and 4 revealed 14 genes that were mis-expressed after culture in either WM or KSOM (Table 6). EASE analysis revealed that five of these 14 down-regulated genes (S/c7a3, Slc15a2, 9030418MORik, Prdx2, Aqp8) belong to the GO transporter activity family, with the first three belonging to the child ontological carrier activity family (Table 7). Solute carrier family 7 is important in the transport of lysine and arginine, whereas solute carrier family 15 is devoted to the transport of oligopeptides. Aquaporin 8 belongs to a class of membrane channel proteins that facilitate bulk water transport (Agre \& Kozono 2003). It is present on the basolateral membranes of the trophectoderm and is probably involved in trans-trophectodermal water movement required for cavitation (Barcroft et al. 2003). It will be of interest to determine if over-expressing Aqp8 stimulates development under either of these culture conditions.

Also of note is the reduced expression of the genes for interleukin-6 (I/6) and for peroxiredoxin 2 (Prdx2). $1 / 6$ function in vivo may stimulate preimplantation embryo development, because the addition of interleukin- 6 to culture media results in an increased cell number in blastocysts, prolonged gestation and increased weight of the generated pups (Cheung et al. 2003). Peroxiredoxin 2 belongs to a newly defined family of antioxidant proteins that have been implicated in cell proliferation and differentiation, intracellular signaling, protecting proteins from

Table 7 EASE analysis of genes differentially expressed after culture in either Whitten's medium or KSOM/AA.

\begin{tabular}{lll}
\hline Gene category & Gene name & Gene description \\
\hline Plasma membrane & Arhu & ras homolog gene family, member U \\
& Lamr1 & RIKEN cDNA 2700094K13 gene \\
& Slc7a3 & solute carrier family 7 (cationic amino acid transporter, y+ system), member 3 \\
& Aqp8 & solute carrier family 15 (H+/peptide transporter), member 2 \\
Transporter activity & Prdx2 & aquaporin 8 \\
& $9030418 M 05 R i k$ & peroxiredoxin 2 \\
& Slc7a3 & RIKEN cDNA 9030418M05 gene \\
& Slc15a2 & solute carrier family 7 (cationic amino acid transporter, y+ system), member 3 \\
& sqp8 & solute carrier family 15 (H+/peptide transporter), member 2 \\
\end{tabular}


oxidative damage, and apoptosis (Fujii \& Ikeda 2002). Prdx2 down-regulation could contribute to the increase incidence of apoptosis that is observed in cultured embryos, when compared with those that develop in vivo (Brison \& Schultz 1997).

In summary, results presented here highlight the ability of microarray analysis to provide insights into biological processes, in this case preimplantation development. Genes with expression that is affected by culture provide candidates for a standard hypothesis-driven approach to study their function.

\section{Acknowledgements}

This research was supported by a grant from the NIH (HD 44575 to $\mathrm{R}$ M S) as part of the NICHD Cooperative Program on Female Health and Egg Quality. P R was supported by a training grant from the $\mathrm{NIH}$ (T32-HD40135) and a grant from the American Society of Reproductive Medicine. P R thanks John Tobias of the Penn Biomedical Informatics Facility for basic GeneSpring training and helpful discussions regarding statistical analyses of microarray data, Martin Anger for the pEGFPN2 RNA, and Fanyi Zeng for some material used for analysis of gene expression. P R and R M S thank Daniel Dumesic, John Eppig, Tom Fleming, Dick Tasca and Jeremy Thompson for critically reading the manuscript and for their comments.

\section{References}

Agre P \& Kozono D 2003 Aquaporin water channels: molecular mechanisms for human diseases. FEBS Letters 555 72-78.

Barcroft LC, Offenberg H, Thomsen P \& Watson AJ 2003 Aquaporin proteins in murine trophectoderm mediate transepithelial water movements during cavitation. Developmental Biology 256 $342-354$

Biggers JD, McGinnis LK \& Raffin M 2000 Amino acids and preimplantation development of the mouse in protein-free potassium simplex optimized medium. Biology of Reproduction 63 281-293.

Brison DR \& Schultz RM 1997 Apoptosis during mouse blastocyst formation: evidence for a role for survival factors including transforming growth factor $\alpha$. Biology of Reproduction 56 1088-1096.

Cheung LP, Leung HY \& Bongso A 2003 Effect of supplementation of leukemia inhibitory factor and epidermal growth factor on murine embryonic development in vitro, implantation, and outcome of offspring. Fertility and Sterility 80 (Suppl 2) 727-735.

Doherty AS, Mann MR, Tremblay KD, Bartolomei MS \& Schultz RM 2000 Differential effects of culture on imprinted H19 expression in the preimplantation mouse embryo. Biology of Reproduction 62 1526-1535.

Ecker DJ, Stein P, Xu Z, Williams CJ, Kopf GS, Bilker WB, Abel T \& Schultz RM 2004 Long-term effects of culture of preimplantation mouse embryos on behavior. PNAS 101 1595-1600.

Erbach GT, Lawitts JA, Papaioannou VE \& Biggers JD 1994 Differential growth of the mouse preimplantation embryo in chemically defined media. Biology of Reproduction 50 1027-1033.

Fleming TP, Sheth B \& Fesenko I 2001 Cell adhesion in the preimplantation mammalian embryo and its role in trophectoderm differentiation and blastocyst morphogenesis. Frontiers in Bioscience 6 D1000-D1007.

Fujii J \& Ikeda Y 2002 Advances in our understanding of peroxiredoxin, a multifunctional, mammalian redox protein. Redox Report $7123-130$
Hamatani T, Carter MG, Sharov AA \& Ko MS 2004 Dynamics of global gene expression changes during mouse preimplantation development. Developmental Cell 6 117-131.

Handyside AH \& Hunter S 1984 A rapid procedure for visualizing the inner cell mass and trophectoderm nuclei of mouse blastocysts in situ using polynucleotide-specific fluorochromes. Journal of Experimental Zoology 231 429-434.

Ho Y, Wigglesworth K, Eppig JE \& Schultz RM 1995 Preimplantation development of mouse embryos in KSOM: augmentation by amino acids and analysis of gene expression. Molecular Reproduction and Development $41232-238$.

Hosack DA, Dennis G Jr, Sherman BT, Lane HC \& Lempicki RA 2003 Identifying biological themes within lists of genes with EASE. Genome Biology 4 R70.

Kalab P, Pu RT \& Dasso M 1999 The Ran GTPase regulates mitotic spindle assembly. Current Biology 9 481-484.

Ko MS, Kitchen JR, Wang X, Threat TA, Hasegawa A, Sun T, Grahovac MJ, Kargul GJ, Lim MK, Cui $Y$, Sano $Y$, Tanaka T, Liang $Y$, Mason S, Paonessa PD, Sauls AD, DePalma GE, Sharara R, Rowe LB, Eppig J, Morrell C \& Doi H 2000 Large-scale cDNA analysis reveals phased gene expression patterns during preimplantation mouse development. Development 127 1737-1749.

Lane M 2001 Mechanisms for managing cellular and homeostatic stress in vitro. Theriogenology 55 225-236.

Lane M \& Gardner DK 2003 Ammonium induces aberrant blastocyst differentiation, metabolism, $\mathrm{pH}$ regulation, gene expression and subsequently alters fetal development in the mouse. Biology of Reproduction 69 1109-1117.

Latham KE, Garrels JI, Chang C \& Solter D 1991 Quantitative analysis of protein synthesis in mouse embryos. I. Extensive reprogramming at the one- and two-cell stages. Development 112 921-932.

Lessey BA 2002 Adhesion molecules and implantation. Journal of Reproductive Immunology 55 101-112.

Levy S, Todd SC \& Maecker HT 1998 CD81 (TAPA-1): a molecule involved in signal transduction and cell adhesion in the immune system. Annual Review of Immunology 16 89-109.

Liu Y, Helms AW \& Johnson JE 2004 Distinct activities of Msx1 and Msx3 in dorsal neural tube development. Development 131 1017-1028.

Ma J, Svoboda P, Schultz RM \& Stein P 2001 Regulation of zygotic gene activation in the preimplantation mouse embryo: global activation and repression of gene expression. Biology of Reproduction $641713-1721$.

Natale DR, De Sousa PA, Westhusin ME \& Watson AJ 2001 Sensitivity of bovine blastocyst gene expression patterns to culture environments assessed by differential display RT-PCR. Reproduction 122 687-693.

Niemann H \& Wrenzycki C 2000 Alterations of expression of developmentally important genes in preimplantation bovine embryos by in vitro culture conditions: implications for subsequent development. Theriogenology 53 21-34.

Niwa H, Miyazaki J \& Smith AG 2000 Quantitative expression of oct-3/4 defines differentiation, dedifferentiation or self-renewal of ES cells. Nature Genetics 24 372-376.

Quimby BB \& Dasso M 2003 The small GTPase Ran: interpreting the signs. Current Opinion in Cell Biology 15 338-344.

Sharov AA, Piao Y, Matoba R, Dudekula DB, Qian Y, VanBuren V, Falco G, Martin PR, Stagg CA, Bassey UC, Wang Y, Carter MG, Hamatani T, Aiba K, Akutsu H, Sharova L, Tanaka TS, Kimber WL, Yoshikawa T, Jaradat SA, Pantano S, Nagaraja R, Boheler KR, Taub D, Hodes RJ, Longo DL, Schlessinger D, Keller J, Klotz E, Kelsoe G, Umezawa A, Vescovi AL, Rossant J, Kunath T, Hogan BL, Curci A, D'Urso M, Kelso J, Hide W \& Ko MS 2003 Transcriptome analysis of mouse stem cells and early embryos. PLoS Biology $1 \mathrm{E} 74$.

Stacey DW 2003 Cyclin D1 serves as a cell cycle regulatory switch in actively proliferating cells. Current Opinion in Cell Biology $\mathbf{1 5}$ 158-163. 
Summers MC, McGinnis LK, Lawitts JA, Raffin M \& Biggers JD 2000 IVF of mouse ova in a simplex optimized medium supplemented with amino acids. Human Reproduction 15 1791-1801.

Suzuki A, Yamanaka T, Hirose T, Manabe N, Mizuno K, Shimizu M, Akimoto K, Izumi Y, Ohnishi T \& Ohno S 2001 Atypical protein kinase $C$ is involved in the evolutionarily conserved par protein complex and plays a critical role in establishing epithelia-specific junctional structures. Journal of Cell Biology 152 1183-1196.

Takahashi Y, Bigler D, Ito Y \& White JM 2001 Sequence-specific interaction between the disintegrin domain of mouse ADAM 3 and murine eggs: role of beta1 integrin-associated proteins CD9, CD81, and CD98. Molecular Biology of the Cell 12 $809-820$.

Tepass U 2003 Claudin complexities at the apical junctional complex. Nature Cell Biology 5 595-597.

Wang QT, Piotrowska K, Ciemerych MA, Milenkovic L, Scott MP, Davis RW \& Zernicka-Goetz M 2004 A genome-wide study of gene activity reveals developmental signaling pathways in the preimplantation mouse embryo. Developmental Cell 6 133-144.
Watson AJ \& Barcroft LC 2001 Regulation of blastocyst formation. Frontiers in Bioscience 6 D708-D730.

Whitten WK 1971 Nutrient requirements for the culture of preimplantation mouse embryo in vitro. Advances in Bioscience 6 129-139.

Xu C, Liguori G, Persico MG \& Adamson ED 1999 Abrogation of the Cripto gene in mouse leads to failure of postgastrulation morphogenesis and lack of differentiation of cardiomyocytes. Development 126 483-494.

Zeng F \& Schultz RM 2003 Gene expression in mouse oocytes and preimplantation embryos: use of suppression subtractive hybridization to identify oocyte- and embryo-specific genes. Biology of Reproduction 68 31-39.

Received 30 April 2004

First decision 8 June 2004

Accepted 19 June 2004 